\title{
THE CENTER FOR CLAIMS RESOLUTION
}

\author{
LAWRENCE FitzPatrick*
}

This article was written in 1989 shortly after the related conference on mass settlement of mass torts. ${ }^{1}$ Although some of the data is necessarily dated, the article is included here as written to provide an historical perspective. The appendix updates much of the relevant data.

\section{INTRODUCTION}

The Center for Claims Resolution, Inc. ("the Center") was formed on October 6, 1988 to handle asbestos-related personal injury claims filed against its members. The members of the Center are all former members of the Asbestos Claims Facility, which was officially dissolved on October 3, 1988 after three years of operation. The Center strives to deal with the asbestos personal injury problem in a rational, responsible, and cost-effective manner.

This article traces the accomplishments of the Asbestos Claims Facility during its three years of existence and discusses the structural problems that eventually resulted in its dissolution. It also discusses the formation of the Center for Claims Resolution, structural changes in the Center designed to eliminate the problems that led to the Facility's dissolution, and the goals and objectives of the Center.

\section{Formation and Dissolution of the Asbestos Claims Facility}

On June 19,1985, thirty-two producers of asbestos or asbestos containing products ("producers") and sixteen insurers ("insurers") signed an agreement concerning mass resolution of asbestos-related claims. This Agreement is known as the Wellington Agreement because of the role played by Harry Wellington, then-Dean of the Yale University Law School, as a facilitator in the negotiations between the producers and the insurers. The Wellington Agreement resolved dozens of actual and potential lawsuits between the producers and their insurers over insurance coverage for asbestos losses. The agreement also established a nonprofit organization, the Asbestos Claims Facility ("the Facility"), to administer and arrange for the

Copyright $@ 1990$ by Law and Contemporary Problems

- President and chief executive officer, Center for Claims Resolution.

1. A Conference on Mass Settlement of Mass Torts, Research Triangle Park, North Carolina (April 28-29, 1989) (presented by Duke University School of Law and, its affiliate, the Private Adjudication Center, Inc.). 
evaluation, settlement, payment, or defense of all asbestos-related personal injury claims against subscribing producers and insurers.

The Facility began handling claims for its members in September 1985. During the initial stages of operation, it operated through employees borrowed from its members. The Facility began hiring permanent staff during the spring of 1986 and was fully staffed and operational by August 1986.

Despite serious structural problems, the Facility achieved several significant accomplishments in its three years of existence. First, it dramatically increased the number of asbestos claims resolved. As best can be determined from historical records, Facility members resolved approximately 6,000 claims in the ten-plus years of asbestos litigation that preceded the creation of the Facility. ${ }^{2}$ In its three years of operation, the Facility disposed of more than 18,500 asbestos claims. ${ }^{3}$ While some criticized the Facility for not settling claims fast enough and far enough in advance of trial, the Facility clearly increased the disposition rate of asbestos claims by a substantial margin.

The Facility also implemented programs to deal with asbestos claimants who show signs of exposure to asbestos, but who do not show signs of impairment as a result of that exposure. Prior to the inception of the Facility, such claimants often were forced to file lawsuits to avoid being barred by statutes of limitations, and they ultimately ended their lawsuits by compromising their claims for relatively nominal amounts. Claimants who subsequently developed serious asbestos-related illness often found themselves precluded from additional compensation because of their prior settlements. The Facility instituted "Green Card" and "Pleural Registry" programs for such claimants. Under these programs, the Facility waived the limitation periods and placed the claims on inactive status. If a claimant subsequently became impaired from asbestos exposure, the claimant could seek full compensation for the injury. In its three years of existence, the Facility recorded over 5,500 such dispositions. During the first half of 1988 , the number of such cases placed on inactive status exceeded the number of cash settlements.

The Facility also reduced the transactional costs associated with the processing of asbestos claims. Before the Facility was created, approximately 1,100 law firms represented asbestos defendants nationwide. Upon inception, the Facility reduced this number to sixty-three and later reduced the number to fifty-five. While quantifying the exact amount of savings attributable to the Facility is difficult because the volume of the asbestos problem significantly increased after the Facility was created, the Facility clearly saved its members substantial sums in defense costs by limiting the number of law firms in the

2. This historical information was derived from the aggregation of settlement data submitted to the Facility by its members when the Facility was formed.

3. This number refers to cash dispositions. Approximately 5,500 claims also were disposed of through Green Card and Pleural Registry programs, which are discussed more fully below. 
overall defense effort. The Wellington Agreement prohibited cross-claims and third-party complaints among Facility members, thus saving additional transaction costs.

Finally, from the perspective of its members, the Facility materially improved the trial results in those cases that were tried to a verdict. Before the Facility was created, the defendants prevailed in approximately 28 percent of the cases that went to verdict. In the remaining cases, the plaintiffs' average award was approximately $\$ 600,000.4$ With the creation of the Facility and centralization of the defense of its members in one law firm per jurisdiction, the Facility defendants prevailed in approximately 65 percent of the cases that proceeded to verdict, and the average adverse verdict was approximately $\$ 330,000$.

Since its inception, however, the Facility was plagued by three serious structural problems that eventually led to its dissolution. The first problem involved the predetermined shares of each settlement to be paid by the producers. The Center calculated the shares based on the producers' experience in the tort system before the creation of the Facility. At the time the shares were originally calculated, the only kinds of asbestos claims were essentially shipyard claims and claims brought by insulators who worked with asbestos-containing products. After the formation of the Facility, the number of new asbestos claims dramatically increased and the occupational mix of the new claims significantly shifted. While claims continued to be received from shipyard workers and insulators, there was also an influx of new claims from other occupations, such as tire workers, rubber workers, and steel workers. Some producers claimed it was unfair to apply their shares, which were derived primarily from shipyard and insulator experience, to these new kinds of claims. While the sharing formula under the Wellington Agreement did have a provision for share adjustment, it contained a relatively inflexible cap, providing that no producer's share could change by more than 15 percent because of any one prospective adjustment. In the opinion of at least some producers, the Wellington Agreement's sharing formula was too inflexible to account for the changing mix of the new claims.

The second structural problem related to governance. The Facility was established basically as a one company-one vote organization. Some members thought this allowed members with small shares to combine and out-vote members with larger shares on some key governance questions.

The third structural problem was philosophical. Facility members came to the Facility with widely divergent claims-handling philosophies and vast differences in available assets to deal with their shares of settlements. Some members favored an aggressive claims philosophy and increased disposition rates. Other members favored a more conservative claims handling approach

4. Information derived from a study of verdicts reported in Mealey's Litigation ReportAsbestos (Mealey Publications, Inc.) and Asbestos Litigation Reporter (Andrews Publications). The information was confirmed by cross-checking against a historical record of asbestos case verdicts maintained by a major Facility insurer. 
and disfavored settlements beyond those mandated by the tort system trial calendar. Similarly, some members favored litigating asbestos claims perceived to be meritless, and other members opposed litigating the claims in most circumstances. Rather than improving over time, these philosophical splits were exacerbated by the increasing volume of new asbestos claims and the multiplication of the number of asbestos claims set for trial.

On July 31, 1987, prompted at least in part by these structural problems, Owens Corning Fiberglas Corporation ("OCF") became the first member to withdraw from the Facility. OCF complied with the terms of the Wellington Agreement, under which a producer could withdraw its designation of the Facility as its claims-handling agent only with respect to the claims filed sixty days after notice of withdrawal was given.

During August and September 1987, several other major Facility producers expressed dissatisfaction with their liability shares and demanded share relief from other producers. During these two months, the producers held various meetings and made several proposals on share reallocation. On October 7, 1987, however, the producers informed the Facility's board of directors of their inability to agree to a reallocation and that, as a result, seven major producers wished to withdraw from Facility membership.

From October 1987 through February 1988, the Facility membership divided into three groups: the insurers, seven dissatisfied producers, and thirty producers who opted to remain with the Facility. ${ }^{5}$ Numerous meetings during each of these months among and between the three groups concerned potential negotiated withdrawals from the Facility by dissatisfied producers and a reconstituted Facility for the remaining producers.

On February 26, 1988, Eagle-Picher Industries, Inc., one of the dissatisfied producers, filed a complaint against the Facility in the United States District Court for the Southern District of Ohio, ${ }^{6}$ seeking termination of the agency relationship between the Facility and Eagle-Picher, and alleging breach of contract, mutual mistake, breach of fiduciary duty, combination and restraint of trade, and antitrust law violations.

During March and April 1988, Carey Canada, Inc., Celotex Corporation, Fibreboard Corporation, Owens-Illinois, Inc., and Pittsburgh Corning Corporation prospectively withdrew from the Facility. OCF also announced that it no longer believed the Facility was the most effective means of resolving meritorious asbestos-related claims and that it wished to withdraw its pending claims from the Facility.

In response, the Facility's board of directors appointed a special nineperson committee to evaluate the situation and to consider the ramifications of dissolution or reorganization of the Facility. For a variety of reasons,

.5. In addition to the original thirty-two producer signatories, three additional producers joined the Facility after it was formed: A.P. Green Industries, Inc., Porter-Hayden Co., and GAF Corporation.

6. Eagle-Picher Industries, Inc. v Asbestos Claims Facility, Inc., No C1-88-0196 (SD Ohio, filed February 26, 1988). 
including the members' inability to agree on how to reallocate the shares of withdrawing members such as Eagle-Picher, and increasing nonpayment of Facility bills by some Facility members, the Facility was drawn inexorably toward dissolution.

On June 15, 1988, a substantial majority of Facility members agreed to dissolve the Facility effective October 3, 1988. In the interim, the Facility members pledged to use their best efforts to establish a new claims-handling organization for those members that desired one. On September 1, 1988, Facility members voted to dissolve the Facility, and, on October 3, 1988, members filed a certificate of dissolution with the Delaware Secretary of State.

III

\section{Formation of the Center for Claims Resolution}

Contemporaneously with the dissolution of the Facility, twenty-one companies announced the creation of the Center for Claims Resolution. While the twenty-one founders of the new claims-handling organization are all former members of the Facility, ${ }^{7}$ the Center is neither a continuation of nor successor to the Facility. It is independently funded and operated. Unlike the Facility, insurance companies are not members of the Center. However, virtually all insurers that were formerly members of the Facility and whose policyholders joined the Center have signed an agreement to support the Center's operational costs.

In an effort to eliminate the major structural problems that had plagued the Facility, the Center differs from the Facility in several respects. First, the Center has a much more flexible sharing formula for liability payments and expenses, which determines producer shares across four different time periods and a dozen occupational categories. In certain new categories of cases in which the data are insufficient to establish a rational sharing formula, the formula provides for per capita sharing among the members until a reasonable permanent sharing formula can be derived. The new sharing formula removes the Wellington Agreement's 15 percent cap on prospective adjustment. The Center will maintain detailed data concerning pending claims and will generate reports necessary for monitoring of the new sharing formula. The new sharing formula promises to result in a formula that more accurately reflects the changing nature of asbestos claims; its safeguards and procedures also should provide additional fairness and flexibility.

Second, in response to the governance problem, the Center weights members' votes according to each members' share of liability and expenses. Unlike the Facility, the Center thus strikes a balance between the right of each

7. The twenty-one companies that are members of the Center are: A.P. Green Industries, Inc.; Armstrong World Industries, Inc.; CertainTeed Corporation; C.E. Thurston \& Sons, Inc.; Dana Corporation; Flexitallic, Inc.; GAF Corporation; IU North America, Inc.; Keene Corporation; Maremont Corporation; National Gypsum Company; NOSROC, Inc.; Nuturn Corporation; Pfizer Inc.: Quigley Company, Inc.; $\mathrm{T} \& \mathrm{~N}$; United States Gypsum Company; and four confidential members. 
member to have a vote and the substantial disparity in the financial participation of its members.

Finally, all members of the Center have agreed to a claims-handling philosophy providing for the early resolution of meritorious asbestos claims. According to this philosophy, the Center will attempt to settle all meritorious claims on the Trial List $^{8}$ significantly before the scheduled trial date. A substantial portion of the Center's estimated annual indemnity payments also will be used to resolve non-Trial List asbestos claims that further the goals of the Center and reduce the backlog of asbestos claims pending against its members.

\section{IV \\ Objectives of the Center}

The Center is focusing on the following goals and objectives for the asbestos claims of its members: (1) early resolution of meritorious asbestos claims; (2) resistance and, if necessary, litigation of nonmeritorious asbestos claims; (3) establishment and maintenance of credibility with the judiciary, claimants, members of the plaintiffs' bar, and the public; (4) development of appropriate short-term and long-term strategic plans to fulfill the mission of the Center while maintaining the flexibility to respond to changing circumstances; (5) reduction of allocated legal expenses through internalization of functions currently performed by outside counsel, while maintaining quality representation; (6) reduction of unallocated operating expenses through increased efficiency and productivity within the Center; and (7) attraction, development, and retention of high quality professional and support staff.

To achieve these goals and objectives, the Center will take various actions. As mentioned above, the Center will dispose of all appropriate asbestos claims on the Trial List in a timely and cost-effective manner, and of non-Trial List asbestos claims that further the goals of the Center and reduce the backlog of asbestos claims pending against its members. The Center also will resolve asbestos claims at a level that accurately reflects the exposures of the Center's members, and will continue and expand non-cash disposition programs, such as Pleural Registries and Green Cards. The filing of nonmeritorious asbestos claims will be resisted, and more creative and innovative methods to dispose of asbestos claims will be developed. Finally, to meet its goals and objectives, the Center will develop training programs for Claims Division personnel.

The Center also will dramatically reduce its aggregate defense expenses by (1) internalizing numerous claims-handling functions, currently performed by

8. "Trial List claims" are asbestos claims that have received trial dates in the jurisdictions in which they are pending. While the backlog for trials of asbestos claims varies substantially from jurisdiction to jurisdiction, claims on the trial list generally have been pending in the tort system for at least three years, and sometimes substantially longer. 
outside counsel, that can be more efficiently and cost-effectively performed by the Center's staff; (2) achieving the early disposition of all meritorious claims on the Trial List; and (3) participating initially in counsel-sharing arrangements with various non-members. ${ }^{9}$

To deal effectively with the asbestos problem over time, the Center also will devote resources to achieving long-term goals. Among the long-term goals to be addressed by the Center are:

1. Processing of claims, not lawsuits. The Center will institute programs to resolve asbestos claims that have not yet been filed as lawsuits. The Center's staff will receive claims directly from claimants, and will conduct an investigation and secure an appropriate independent medical examination whenever necessary. At the close of the investigation, an evaluation and negotiation period will commence. The claim will be settled for a fair value or denied as nonmeritorious. Alternative dispute resolution mechanisms will be utilized for those claims with a genuine dispute as to value. ${ }^{10}$

2. Independent medical examinations. The Center will consider the development of a network of independent physicians to perform medical examinations of claimants. These physicians would examine the patient, provide evaluations based on a standard protocol, and submit reports in a predetermined format. Members of the network would not be used as trial experts, thereby enhancing their credibility with, and acceptability to, the plaintiffs' bar. The Center has received a preliminary study of the feasibility of establishing such a network of examining physicians with various specialties.

3. New uses of Green Cards. The Center will attempt to expand the Green Card deferral programs that were successfully used by the Facility. For example, the Center may offer a Green Card with a promise to investigate and to attempt to negotiate a resolution of a claim within a specified period upon manifestation of an asbestos-related disease.

4. Encouragement of limited releases. With the expansion of the Green Card program, the Center will consider encouraging the use of limited releases. For example, in cases not involving malignancies, the claimant would be offered a limited release

9. Under such arrangements, the Center's members that are defendants in a particular case and other nonmember defendants in the same case may share the services of a single law firm to represent them in virtually all aspects of the case except for settlement negotiations and conductrelated trials. Services of the shared law firm are billed to each defendant on a per capita basis, and the Center is billed for the per capita shares of its members named in the particular case.

10. The types of alternative dispute resolution mechanisms the Center will utilize vary widely among jurisdictions. The Center is very flexible in this regard and is willing to consider any reasonable alternative to the tort system. 
and would be encouraged to settle for a reduced dollar amount. Should a malignancy subsequently develop, the claimant would then be allowed to present another claim.

5. Improved relationships with unions. With the other long-term programs proposed by the Center, including the program of independent examinations, the Center will develop an effective program for dealing with the unions representing potential claimants. Such a program would explain the Center's various programs and detail its claims-handling philosophy.

6. Branch legal offices in target regions. On an as-needed basis, the Center will consider establishing small branch legal offices in target regions to handle routine litigation functions. The development of these branch offices would greatly reduce allocated defense expenses in high-volume areas, while not sacrificing quality legal representation.

7. Improved communication with the judiciary, press, and plaintiff' bar. The Center will develop a program of affirmative, rather than reactive or defensive, public relations. In so doing, it is contemplated that the Center will initiate periodic meetings with judges and with plaintiffs' counsel to solicit their input about its programs.

8. Cancer insurance or life insurance programs. The Center will consider the implementation of a program that would provide life insurance as a means of disposing of claims. Such insurance could be triggered to pay proceeds upon confirmation or diagnosis of a malignancy. The Center would need to find an insurance company willing to provide a product resembling group-life insurance. In exchange for the policy, the Center would pay a premium for each nonmalignancy case that is settled.

$\mathrm{V}$

\section{Administration and Funding of the Center}

The Center's headquarters and its national claims office are located in Princeton, New Jersey. The Center's annual operating budget during its first year of existence was approximately $\$ 15.0$ million. The operating budget is expected to increase substantially in subsequent years as the Center expands its staff and continues to internalize functions. Supporting insurers pay for approximately 70 percent of the operating expenses of the Center. The producer members pay the remaining 30 percent under a tiered agreement, with larger producers paying a larger share.

The Center currently employs approximately sixty professionals in its operations (claims and legal) branch and an additional sixty persons in its administrative (for example, financial and data processing) branch. The 
number of employees in the operational branch is expected to expand substantially over the near term and should reach approximately 100 by the end of 1989.

The Center pays its indemnity and defense commitments by billing the insurers for their shares of each Center commitment. Generally speaking, the insurance coverage provisions of the Wellington Agreement were carried over intact into the agreement establishing the Center. Accordingly, all producer members of the Center can call upon any insurance policy in effect from the date of first exposure until the date of manifestation to pay on a particular claim.

To facilitate prompt payment of Center indemnity and defense commitments, Center insurers have agreed to thirty days' advance billing of indemnity and defense costs. The Center estimates its settlements and defense costs for each upcoming month and bills its supporting insurers. The insurers pay the Center based upon the estimates, and the Center in turn compensates both claimants and defense counsel. As settlements are consummated and per claim data becomes available, the estimated bills are retroactively adjusted to conform to the Center's actual experience. This procedure should enable the Center to avoid the chronic late payments experienced by the Facility.

The Center has no particular problems with matters related to funding such as timing and contingencies. Funding is available on a current basis for all Center commitments; this situation is not expected to change during the existence of the Center.

\section{VI}

\section{Center Claims Processing}

The Center does not settle asbestos claims pursuant to a predetermined schedule of benefits. The Center staff analyzes each asbestos claim individually and makes what it considers to be a fair offer on behalf of its members. In analyzing asbestos claims, the Center staff considers several factors, including the severity of the disease, the degree to which Center members contributed to the disease process relative to contributions by nonmembers, and legal trends in the jurisdiction where the claim has been filed.

The Center's analysis of each claim on an individual basis does not preclude it from settling asbestos claims in blocks or groups. The vast majority of the claims settled to date have been disposed of in group fashion after the Center staff reviewed each claim individually. Given the scope of the asbestos problem, the Center sees no practical alternative to this approach.

Although the Center readily accepts claims filed by unrepresented claimants, more than 99 percent of the claims currently being handled by the Center involve claimants represented by counsel. Since the Center membership nearly always represents only a relatively small percentage of the total causation in any given claim, and since the claimant probably will have to 
proceed in the tort system against recalcitrant, nonmembers who refuse to settle, the Center does not anticipate this situation changing in the foreseeable future.

The Center staff typically negotiates settlements directly with counsel for the claimants. In a few jurisdictions, however, outside attorneys negotiate for the Center. The relationship between the Center staff and the asbestos plaintiffs' bar can be fairly characterized as "friendly adversaries." Compared to history and to the current positions of most non-Center producers, the Center staff has engaged in unprecedented dialogue with the attorneys representing asbestos claimants.

During the first four months of its existence, the Center made several positive strides. First, it disposed of more than 12,300 claims. By way of comparison, as noted above, there were approximately 6,000 total dispositions in the ten-plus years of asbestos litigation before the Facility was created, and the Facility disposed of approximately 18,500 claims in its three years of existence.

Second, the Center has resolved the 12,300 claims at average values that compare very favorably with the historical shares of its members in settlements, both before and during the existence of the Facility.

Third, the Center has decreased the backlog of asbestos claims pending against its members. Approximately 61,000 claims were pending against Center members when the Center commenced operation in October 1988. By January 31, 1989, the Center had reduced that number to 57,000 , despite an increase in new filings during the period. Of the 57,000 pending claims, approximately 8,000 (14 percent) were from nontraditional occupations, ${ }^{11}$ which the Center did not intend to settle in the same manner as traditional claims, Furthermore, approximately 36,000 of the pending claims (63 percent) represented claims filed from 1987 through 1989. Thus, the Center made substantial progress in settling the older, more meritorious claims against its members.

Fourth, the Center has managed to limit the number and amount of adverse trial verdicts against its members. As best the Center can determine, there have been adverse verdicts against non-Center producers in excess of $\$ 240$ million since the breakup of the Facility. The Center, in contrast, has been forced to go to verdict only a handful of times during the last four months and has generally prevailed at trial or received relatively small adverse verdicts. ${ }^{12}$

11. Claims from workers in nontraditional occupations-tireworkers, for example-generally involve claimants who were not directly exposed to asbestos during the course of their employment. In such cases, the asbestos exposure, if any, arises merely from the presence of asbestos-containing products in the factory or workplace in which the claimants were employed. Many such claims arise out of mass screenings, which are arranged and sometimes financed by plaintiff' attorneys.

12. The average adverse verdict against nonmembers, excepting verdicts generally perceived as aberrational, such as the $\$ 152$ million recently awarded to two plaintiffs in Maryland and the $\$ 32$ million awarded to five plaintiffs in Delaware, has been approximately $\$ 947,000$. The average adverse verdict during the existence of the Facility was approximately $\$ 330,000$. The average adverse verdict against Center members thus far has been approximately $\$ 111,000$. 
Fifth, the Center also has limited its members' defense costs. Most producers who chose not to join the Center have at least informally admitted that their defense costs have roughly doubled since the demise of the Facility. The Center has held defense costs constant for its members and is implementing plans to reduce defense costs substantially in the future.

Finally, the Center has avoided the recent judicial trend to certify class actions or mass consolidations. Although several judges have recently certified such actions, none has yet been certified against any Center members.

The Center's claims-handling performance thus far has been very encouraging. While it is impossible to predict too much based upon only four months' history, Center members seem quite satisfied with the Center's performance.

\section{VII}

\section{Conclusion}

The greatest strengths of the Center for Claims Resolution are its professional, competent staff and a membership that is willing and able to allow that staff to explore proactive, creative approaches to the asbestos personal injury problem. Unlike the Asbestos Claims Facility, for which there was no precedent, the Center was designed with the benefit of prior experience. As a result, the Center expands upon the Facility's significant strengths and positive innovations, but avoids the Facility's most serious problems. With its clearer mission and organizational structure, smaller and more unified membership, and more flexible and refined sharing formula, the Center offers its members the best, and perhaps final, opportunity for private industry to address the asbestos problem in a collective fashion. 


\section{APPENDIX}

\section{A May 1991 UPDATE}

The Center for Claims Resolution has now been in existence for approximately three years. Its headquarters and national claims office are still located in Princeton, New Jersey. The Center has also established a West Coast claims office in San Ramon, California, and a Texas claims office in Richardson, Texas.

The Center has now disposed of more than 46,000 asbestos claims against its members, prevailing in more than half of the cases that have gone to verdict. The average adverse verdict against Center members have been relatively small.

The Center's annual operating budget is now approximately $\$ 17.5$ million and is not expected to change substantially in the short term. Unlike the Center's first year of operation, supporting insurers now pay virtually all of the operating expenses of the Center, with such payments coming out of the insurance coverage of the producer members. Insurers continue to pay advance bills for indemnity and defense costs. The Center has accordingly managed to avoid the chronic late payments experienced by the Facility.

The Center currently employs 113 professionals in its operations (claims and legal) branch and an additional 70 persons in its administrative branch. Staff counsel and claims people do work formerly done by outside counsel. For example, they receive complaints and open the initial files, prepare case releases, conduct discovery, and direct nearly all settlement negotiations. The role and number of Center employees is expected to remain constant over the near term.

During its second year of operation, the Center adopted an administrative claims program for the processing of claims directly without the necessity of litigation. Response for the program has been mixed. While the program has been responsible for the disposal of more than 1,000 claims, the vast majority of claims currently being handled by the Center involve claimants represented by counsel who have filed lawsuits. As the Center members nearly always represent only a small percentage of the total causation in any given claim, and since the claimants probably have to proceed in the tort system against other defendants and in various bankruptcy courts against insolvent companies, the Center does not anticipate any change in this situation.

The Center has implemented several measures to control the transactional cost associated with the processing of asbestos claims. While the Center and other asbestos defendants consider information about defense cost to be confidential, the available evidence indicates that the Center spends far less for defense of all its members than most major asbestos defendants spend defending a single company. The Center and its members continue to be deeply committed to a philosophy of handling asbestos claims in a manner that minimizes the cost of processing meritorious claims. 
In summary, the Center for Claims Resolution has expanded upon the Asbestos Claims Facility's significant strengths and positive innovations and has avoided the Facility's most serious problems. As noted in the main text, the Center offers its members, the judiciary, and the plaintiffs' bar the only opportunity for a private industry to address the asbestos problem in a collective fashion. To date, the Center appears to be accomplishing its goals and objectives in a manner that can sustain its membership and keep it a viable organization. 
